\title{
Characteristics of unilateral main bronchus obstruction and differentiation from chronic obstructive pulmonary disease by spirometry
}

\author{
Wen Sun, Guang-Fa Wang, Wei Zhang, Hong Zhang, Ying Liu, Cheng-Li Que \\ Department of Pulmonary and Critical Care Medicine, Peking University First Hospital, Beijing, China \\ Contributions: (I) Conception and design: W Sun, CL Que; (II) Administrative support: All authors; (III) Provision of study materials or patients: \\ All authors; (IV) Collection and assembly of data: W Sun, CL Que, Y Liu; (V) Data analysis and interpretation: W Sun, CL Que; (VI) Manuscript \\ writing: All authors; (VII) Final approval of manuscript: All authors. \\ Correspondence to: Cheng-Li Que. Department of Pulmonary and Critical Care Medicine, Peking University First Hospital, No. 8 Xishiku Street, \\ Xicheng District, Beijing 100034, China. Email: quechengli@bjmu.edu.cn.
}

\begin{abstract}
Background: Pattern of flow-volume (F-V) loop in unilateral main bronchus obstruction (UMBO) is under-represented and sometimes misinterpreted as chronic obstructive pulmonary disease (COPD).

Methods: A cross-sectional study was performed among patients with UMBO and COPD confirmed by bronchoscopy, radiographic imaging and spirometry from 2006 to 2019. Data were extracted from electronic medical records. Spirometry data and flow-volume curves (F-V curves) were analyzed. Expiratory F-V curve was classified as monophasic or biphasic according to the absence or presence of breakpoint separating two distinct slopes. Propensity score method was used to reduce the selection bias, and logistic analysis in combination with decision tree approach was performed to explore the differences among groups.

Results: Fifty-six patients with UMBO, 121 individuals with COPD and 68 healthy subjects were included. Typical biphasic expiratory F-V curve was observed in 57.1\% in UMBO group, especially of grade II (stenosis was $51-90 \%$ ), and in $46.3 \%$ in COPD group, while biphasic inspiratory curve presented in $7.1 \%$ of UMBO, and none in COPD. In UMBO, breakpoints tended to appear gradually and smoothly between $\mathrm{MEF}_{75}$ and MEF50, whereas in COPD they often occurred abruptly and rigidly, ahead of $\mathrm{MEF}_{75}$.

Conclusions: The characteristics of F-V curve, apart from biphasic pattern, the location and configuration of breakpoint in expiratory curve, seemed to be important features of UMBO, which might help to differentiate them from COPD. More data is needed to validate these findings.
\end{abstract}

Keywords: Biphasic pattern; chronic obstructive pulmonary disease (COPD); flow-volume curve (F-V curve); spirometry; unilateral main bronchus obstruction

Submitted Aug 11, 2020. Accepted for publication Feb 22, 2021.

doi: $10.21037 /$ jtd-20-2649

View this article at: http://dx.doi.org/10.21037/jtd-20-2649

\section{Introduction}

Spirometry, especially the flow-volume curve (F-V curve), is an important clue to detect airflow limitation, not only in small airway disease, such as chronic obstructive pulmonary disease (COPD), but also in upper airway obstruction.

Unilateral main bronchus obstruction (UMBO), unlike upper airway obstruction, in which typical patterns were widely accepted and proved to be clinically useful (1), was used to be an uncommon event and more variable in the configuration of F-V curve. UMBO may produce a "classic" biphasic F-V curve (2-4), which was speculated that the unaffected lung dominated the early descending limb of forced expiration and inspiration and the partially obstructed lung contributed to the later part of the maneuver.

However, in clinical practice, UMBO can be easily missed or diagnosed as COPD or asthma, even at 
scrutinization of the flow-volume curve. There is only morphological description of biphasic F-V curve pattern, a lack of comparison with normal subjects and patients with small airway diseases $(2,3)$. Moreover, sample size was relatively small in previous study (4). In this study, we tried to delineate the shape and data of the F-V curve in patients with UMBO, and to find the difference from those of COPD and the normals. We present the following article in accordance with the STROBE reporting checklist (available at http://dx.doi.org/10.21037/jtd-20-2649).

\section{Methods}

\section{Study population}

\section{Inclusion criteria}

We performed a retrospective cross-sectional study and reviewed clinical charts, pulmonary function test (PFT), chest CT, bronchoscopic record, and pathological reports from electronic medical records in the hospital information system for all patients who were diagnosed as UMBO by chest computed tomography (CT) and confirmed by bronchoscopy between October 2006 and December 2019 at Peking University First Hospital. This human study was approved by the Institutional Review Board of the Peking University First Hospital Biomedical Research Ethics Committee (2020-123) with a waiver of informed consent.

The study was conducted in accordance with the Declaration of Helsinki (as revised in 2013).

\section{Exclusion criteria}

We excluded patients comorbid with small airway diseases, such as COPD, asthma and bronchiectasis; patients with airway stenoses more than or other than UMBO, including tracheal, lobar, segmental or subsegmental bronchial stenosis; patients with atelectasis or obstructive pneumonia; patients with comorbidities which might impair ventilation, such as interstitial lung disease, pleural diseases, or neuromuscular disorders; post-operative patients after pneumonectomy or lobectomy.

During the same period, patients diagnosed as COPD only with both lung function tests and CT scan available (no history of lung volume reduction surgery) were included. Meanwhile, healthy subjects who had normal PFT and normal or otherwise normal chest CT except for solitary pulmonary nodules were included. Some of them underwent bronchoscopy for incidental pulmonary nodules and mild respiratory symptoms, confirming the patency of accessible airways, and had no history of respiratory infections in recent three months (Figure 1).

\section{Spirometry and relevant parameters}

PFTs were performed with a MasterScreen PFT System (Jaeger, Germany). All the maximal forced flow-volume maneuvers were technically acceptable with repeatability. The absolute and percent predicted parameters were recorded, including the forced vital capacity (FVC), forced expiratory volume in one second $\left(\mathrm{FEV}_{1}\right)$, the $\mathrm{FEV}_{1} / \mathrm{FVC}$ ratio, the peak expiratory flow (PEF), the expiratory flow with $25 \%, 50 \%$ and $75 \%$ of the FVC expired $\left(\mathrm{MEF}_{75}\right.$, $\mathrm{MEF}_{50}, \mathrm{MEF}_{25}$ ), the peak inspiratory flow (PIF), inspiratory flow when $50 \%$ of FVC inhaled $\left(\mathrm{FIF}_{50}\right)$. Spirometry data was assessed by a qualified pulmonologist who was blinded to subjects.

\section{F-V curve patterns}

Figure 2 presented different patterns of F-V curve. Biphasic $\mathrm{F}-\mathrm{V}$ curve could happen either in expiration or during inspiration only or both. In expiration it is defined as a descending limb with two distinct slopes separated by a breakpoint, and during inspiration it is a curve of two distinct slopes behind PIF. According to the location of breakpoints, the expiratory phase of $\mathrm{F}-\mathrm{V}$ loop was divided into 3 parts, earlier than $\mathrm{MEF}_{75}$, between $\mathrm{MEF}_{75}$ and $\mathrm{MEF}_{50}$; and later than $\mathrm{MEF}_{50}$, and the vicinity of breakpoint was depicted as abrupt with sharp angle or blunt with smooth curvature (Figure 3). Monophasic F-V curve in expiration is a curve of which descending limb, is relatively straight, or flow decrease linearly as lung volume decreases followed by a smooth inspiratory curve after PIF. The rest is curvilinear, a concave shape to the $\mathrm{x}$ axis without breakpoint in expiration and a smooth curve between PIF and the endpoint of inspiration.

\section{Degree of main bronchus obstruction}

The degree of main bronchus obstruction was graded using a proposed central airway obstruction classification system (5-7). Grade I was defined as $\leq 50 \%$ stenosis, grade II was between $51-90 \%$, and grade III was $>90 \%$ stenosis. The degree of airway obstruction was determined under bronchoscope during expiration when the airway caliber was the narrowest in dynamic stenosis. The data was collected by other professional clinicians who were blinded to this study. 


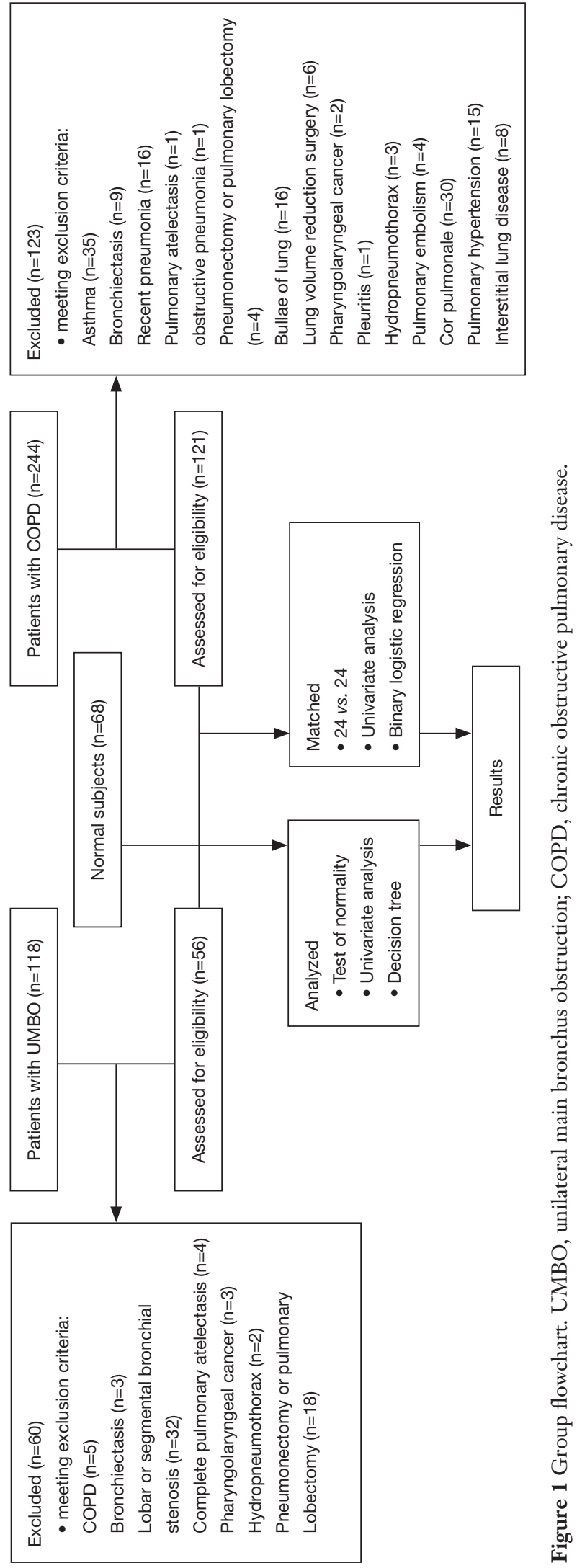

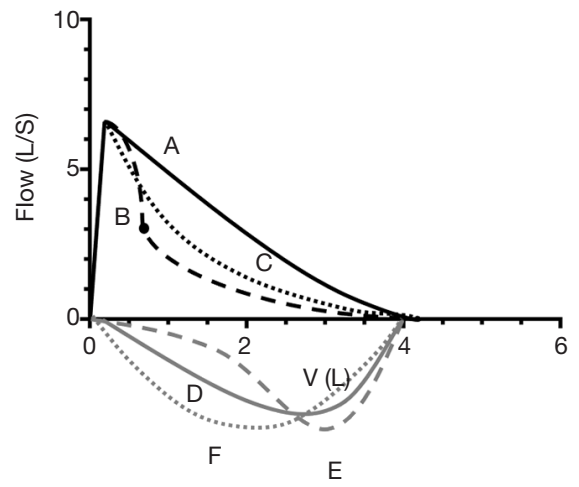

Figure 2 Schematic diagram of representative patterns of concave F-V curves. A, The monophasic expiratory pattern (the black solid line). B, The biphasic expiratory pattern with a breakpoint (the black dashed line). C, The curvilinear expiratory pattern (the black dotted line). D, The monophasic inspiratory pattern (the grey solid line). E, The biphasic inspiratory pattern (the grey dashed line). F, The curvilinear inspiratory pattern (the grey dotted line).

\section{Statistical analysis}

Data were presented as median with interquartile range (IQR) for continuous variables and as frequencies with percentages for categorical variables. All analyses were performed using SPSS 22.0 (SPSS, Chicago, IL, USA) and Graphpad Prism (Graphpad Software, Inc., San Diego, CA, USA). Significance tests were two-sided, and P values of 0.05 or less were considered significant. KruskalWallis test and Chi-Square test were used to evaluate the difference in PFTs. Bonferroni's method, Cramer's V and Spearman's correlation were utilized for analysis. Propensity score method (PSM) was conducted to assess bias and efficiency for further analysis characteristics of UMBO and COPD by spirometry even though this was not a cohort or case-control study (Figure 1). PSM was performed using nearest-neighbor matching by sex and age with the closest propensity score in a 1:1 ratio with the caliper as 0.30 . Binary logistic of univariate and bivariate regressions was used to find out variables closely associated with the recognition of UMBO and COPD group. The decision tree model was generated by the Quick Unbiased Efficient Statistical Tree (QUEST) approach to differentiate UMBO and COPD groups when the variables reached $\mathrm{P} \leq 0.05$ with Bonferroni correction. The final model was built as the simplest structure with minimal risk and generalization error. 

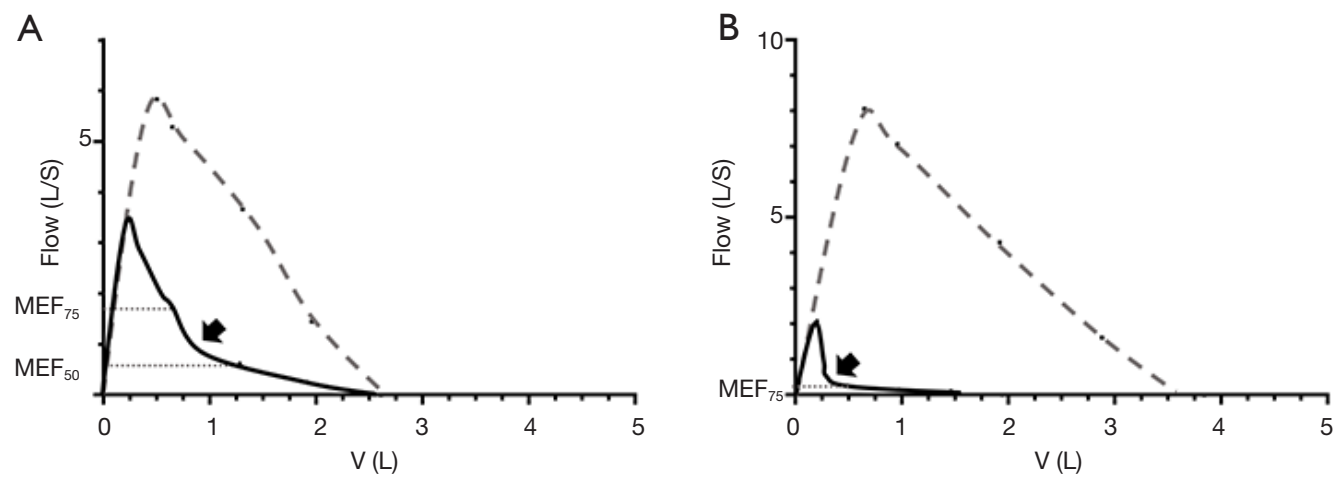

Figure 3 Representative cases of F-V curve in patients with UMBO (A) and COPD (B). The practical curve indicated by a solid line while the predicted curve shown by a dotted line. The arrow indicating the site and the angle of breakpoint. $\mathrm{MEF}_{50}$, maximal expiratory flow with $50 \%$ of FVC expired; $\mathrm{MEF}_{75}$, maximal expiratory flow with $25 \%$ of FVC expired.

Table 1 Demographics of patients with UMBO, COPD and the normal subjects

\begin{tabular}{lccc}
\hline Parameters & UMBO $(\mathrm{n}=56)$ & COPD $^{\S}(\mathrm{n}=121)$ & Normal $(\mathrm{n}=68)$ \\
\hline Age $^{\ddagger}$, years & $55[34-63]$ & $72[66-81]$ & $57[51-65]$ \\
Height ${ }^{\ddagger}$, meter & $1.62(1.60-1.70)$ & $1.68(1.62-1.74)$ & $1.63(1.56-1.71)$ \\
$\mathrm{BMI}, \mathrm{kg} / \mathrm{m}^{2}$ & $22.47(3.58)$ & $22.68(4.18)$ & $23.91(3.37)$ \\
Gender, \% & & & $27(22.3)$ \\
Female & $40(71.4)$ & $94(77.7)$ & $48(66.7)$ \\
Male & $16(28.6)$ & & $24(33.3)$ \\
Smoking history ${ }^{\ddagger}, \%$ & & $91(75.2)$ & $12(17.6)$ \\
Smoker & $10(17.9)$ & $30(24.8)$ & $56(82.4)$ \\
Non-smoker & $46(82.1)$ & &
\end{tabular}

Data were median (IQR), mean (SD) and $\mathrm{n}(\%) .{ }^{\ddagger}$, the $\mathrm{P}$ value was $<0.001$ between COPD group and the other two groups; ${ }^{\S}$, the ratio of emphysema was 39\% (16/41) in GOLD 2, 76.9\% (20/26) in GOLD 3, and 84.6\% (33/39) in GOLD4. UMBO, unilateral main bronchus obstruction; BMI, body mass index; COPD, chronic obstructive pulmonary disease.

\section{Results}

Among 118 patients diagnosed as UMBO by bronchoscopy, 62 were excluded because of co-existence of other airway diseases/stenoses in aforementioned criteria. Eventually, data from 56 patients with UMBO, 121 with COPD and 68 normal subjects were analyzed (Figure 1).

\section{Patient characteristics}

Table 1 showed the demographic and descriptive data in UMBO, COPD and normal group. There were significant differences in gender and smoking history between COPD group and the other two groups $(\mathrm{P}<0.001)$.
In UMBO group, 49 out of 56 patients had left main bronchus obstruction. The degree of bronchial obstruction was mostly grade II $(n=30,53.6 \%)$, and the most common etiology was post-tuberculous bronchial obstruction $(n=24$, $42.9 \%$ ) followed by malignant or benign tumor (Table 2). In COPD group, $87.6 \%$ of the patient had GOLD 2 or higher degree of airflow limitation. With progression of COPD, the emphysema proportion became higher on CT scan.

\section{Comparison of spirometry parameters}

PFT parameters were demonstrated (Table 3). In UMBO group, 33 (58.9\%) patients had $\mathrm{FEV}_{1} / \mathrm{FVC}<0.70$, and $46(82.1 \%)$ had $\mathrm{FEV}_{1}<80 \%$ predicted. In COPD group, 
Table 2 Etiologies of UMBO

\begin{tabular}{|c|c|}
\hline Causes & No. (\%) \\
\hline Post-tuberculosis stenosis & $24(42.9)$ \\
\hline Malignancies & $12(21.4)$ \\
\hline Primary lung cancer & 7 \\
\hline Lung metastases & 1 \\
\hline Myxofibrosarcoma & 1 \\
\hline Lymphoma & 2 \\
\hline Adenoid cystic carcinoma & 1 \\
\hline Benign tumors & $5(8.9)$ \\
\hline Mucinous adenoma & 1 \\
\hline Pulmonary hamartoma & 1 \\
\hline Lipoma & 1 \\
\hline Leiomyoma & 1 \\
\hline Glomus tumor & 1 \\
\hline Inflammation or inflammatory granuloma & $4(7.1)$ \\
\hline Trauma & $4(7.1)$ \\
\hline Granulomatosis with Polyangiitis & $1(1.8)$ \\
\hline Tracheal foreign body & $1(1.8)$ \\
\hline Not determined & $5(8.9)$ \\
\hline \multicolumn{2}{|l|}{ Location of stenosis } \\
\hline Left main bronchus & 49 (87.5) \\
\hline Right main bronchus & $7(12.5)$ \\
\hline \multicolumn{2}{|l|}{ Degree of stenosis } \\
\hline Grade I (0-50\%) & $8(14.3)$ \\
\hline Grade II (51-90\%) & $30(53.6)$ \\
\hline Grade III (91-100\%) & $18(32.1)$ \\
\hline
\end{tabular}

UMBO, unilateral main bronchus obstruction.

the median of $\mathrm{FEV}_{1} / \mathrm{FVC}$ was $0.45(0.31-0.61)$ and $\mathrm{FEV}_{1}$ was $40 \%$ predicted $(23.8-67.1 \%)$. All values of expiratory parameters were significantly different among three groups $(\mathrm{P}<0.001)$.

\section{Analysis of the F-V curve}

During expiration, F-V curve patterns were statistically different among three groups $\left(\chi^{2}=83.91, \mathrm{P}<0.001\right)$ with a moderate correlation. Biphasic F-V curve was observed in $57.1 \%$ of UMBO group, and in $46.3 \%$ of COPD group; monophasic F-V curve was occurred in $32.1 \%$ of $\mathrm{UMBO}$ group, and in $9.1 \%$ of COPD group. Biphasic pattern was not observed in the normal group, while monophasic expiratory F-V curves appeared in $55.9 \%$. Curvilinear type appeared in $10.7 \%$ of patients in UMBO group, compared with $44.6 \%$ in COPD and $44.1 \%$ in normal group.

During inspiration, there were significant differences in F-V curve patterns between UMBO group and the other two groups, but relationship was marginal. Among them, biphasic inspiratory pattern appeared in only 4 (7.1\%) patients in UMBO group (2 with biphasic and 2 with curvilinear expiratory pattern), 1 (1.5\%) in normal group and none in COPD group. The results between groups in this study were shown (Table 4).

When comes to the breakpoints in biphasic pattern, there were significant differences in location and angle between $\mathrm{UMBO}$ and COPD group. Breakpoints was inclined to be located between $\mathrm{MEF}_{75}$ and $\mathrm{MEF}_{50}(\mathrm{n}=16,50.0 \%)$ with blunt angle ( $\mathrm{n}=31,96.9 \%)$ in UMBO, whereas mostly ahead of $\mathrm{MEF}_{75}(\mathrm{n}=54,96.4 \%)$ with sharp angle $(\mathrm{n}=46,82.1 \%)$ in COPD (Table 5 and Figure 3). A significant relationship was shown in location and in angle with different groups.

The decision tree (QUEST) was established for making a properly clinical consideration by several significant factors $(\mathrm{P}<0.001)$. The final model was formed by those who met the study recommendation and consisted of 4 factors, 5 levels of depth, and 14 nodes. As shown by the decision tree algorithm (Figure 4), almost all young and middle-aged patients $(96 \%)$ had the biphasic F-V curve in expiratory with the blunt breakpoint in the UMBO group, and the majority of elderly patients with COPD possessed earlier breakpoint (ahead of $\mathrm{MEF}_{75}$ ) on the biphasic curve (87.9\%). Besides, it is indicated that more than half the normal subjects $(75.0 \%)$ had monophasic pattern of expiratory F-V curve especially at age between 39-64 years old. The decision tree reached good fit with $80.4 \%$ accuracy rate of cases (risk estimate $=0.21$ ).

Different variables among different grade of stenosis in UMBO group were showed (Table 6). Biphasic F-V curve of expiration appeared predominantly in grade II obstruction $(\mathrm{n}=22,73.3 \%)$, while monophasic $\mathrm{F}-\mathrm{V}$ curve was mainly seen in grade III $(n=9,50 \%)$. There were significant differences in location of breakpoints among three grades of stenosis. While the majority of breakpoints in UMBO located between $\mathrm{MEF}_{75}$ to $\mathrm{MEF}_{50}$, breakpoints in grade I or III stenosis were more likely located closer to PEF. All those with breakpoints located after $\mathrm{MEF}_{50}$ turned out to be grade II stenosis ( $\mathrm{n}=7,31.8 \%)$. 
Table 3 Comparison of spirometry and derived parameters among different groups

\begin{tabular}{|c|c|c|c|c|c|c|}
\hline Parameters & \multicolumn{2}{|c|}{ UMBO $(n=56)$} & \multicolumn{2}{|c|}{ COPD $(n=121)$} & \multicolumn{2}{|c|}{ Normal $(n=68)$} \\
\hline $\mathrm{FEV}_{1}, \mathrm{~L}$ & $1.86(1.44-2.07)$ & $64.9(57.8-75.7)$ & $0.95(0.64-1.50)$ & $40.0(23.8-67.1)$ & $2.45(2.23-2.92)$ & $105.0(94.1-116.0)$ \\
\hline FVC, L & $2.61(2.20-3.26)$ & 84.7 (68.5-98.8) & $2.29(1.84-2.82)$ & $75.3(52.1-94.1)$ & $3.04(2.72-3.66)$ & $107.7(97.8-118.5)$ \\
\hline $\mathrm{FEV}_{1} / \mathrm{FVC}, \%$ & $66.8(59.8-76.0)$ & NA & $45.0(30.8-60.7)$ & NA & $80.1(77.8-82.5)$ & NA \\
\hline $\mathrm{MEF}_{50}, \mathrm{~L} / \mathrm{S}$ & $1.26(0.93-1.88)$ & $32.4(22.5-43.5)$ & $0.36(0.24-0.84)$ & $10.5(6.0-23.5)$ & $2.98(2.63-3.81)$ & 79.7 (71.4-95.4) \\
\hline $\mathrm{MEF}_{25}$, L/S & $0.35(0.22-0.56)$ & $22.6(13.9-34.3)$ & $0.16(0.13-0.25)$ & $14.4(10.3-23.4)$ & $0.80(0.63-1.01)$ & $57.7(47.4-71.6)$ \\
\hline $\mathrm{PIF}^{*}, \mathrm{~L} / \mathrm{S}$ & $3.57(3.06-4.53)$ & NA & $3.20(2.42-4.15)$ & NA & $4.62(3.86-5.52)$ & NA \\
\hline $\mathrm{FIF}_{50}{ }^{\ddagger}, \mathrm{L} / \mathrm{S}$ & $3.22(2.65-4.26)$ & NA & $2.79(2.17-3.81)$ & NA & $4.09(3.53-5.10)$ & NA \\
\hline
\end{tabular}

Each value is shown as the median (IQR). $\mathrm{P}$ values of all of the above variables between every two groups were $<0.001$ using KruskalWallis test. * $P$ value was 0.004 between UMBO group and normal group, but there was no significant difference between UMBO group and COPD group ( $P>0.05)$. ${ }^{\ddagger} \mathrm{P}$ value was 0.003 between UMBO group and normal group, but there was no significant difference between UMBO group and COPD group $(\mathrm{P}>0.05)$. UMBO, unilateral main bronchus obstruction; COPD, chronic obstructive pulmonary disease; $\mathrm{FEV}_{1}$, forced expiratory volume in one second; $\mathrm{FIF}_{50}, 50 \%$ of the inspiratory flow; FVC, forced vital capacity; $\mathrm{MEF}_{25}$, maximal expiratory flow with $70 \%$ of FVC expired; $\mathrm{MEF}_{50}$, maximal expiratory flow with $50 \%$ of $\mathrm{FVC}$ expired; $\mathrm{MEF}_{75}$, maximal expiratory flow with $25 \%$ of $\mathrm{FVC}$ expired, peak expiratory flow; PIF, peak inspiratory flow.

Table 4 Cross tabulation of F-V curve pattern among different groups

\begin{tabular}{|c|c|c|c|c|c|c|}
\hline Parameters & UMBO $(n=56)$ & $\operatorname{COPD}(n=121)$ & Normal $(n=68)$ & $\chi^{2}$ & $\mathrm{P}$ & Cramer's V \\
\hline \multicolumn{7}{|c|}{ Expiratory F-V curve, \% } \\
\hline Biphasic & $32(57.1)$ & $56(46.3)$ & $0(0)$ & 83.91 & $<0.001$ & 0.41 \\
\hline Monophasic & $18(32.1)$ & $11(9.1)$ & 38 (55.9) & & & \\
\hline Curvilinear & $6(10.7)$ & $54(44.6)$ & $30(44.1)$ & & & \\
\hline Biphasic & $4(7.1)$ & $0(0)$ & $1(1.5)$ & 17.13 & 0.001 & 0.20 \\
\hline Monophasic & $12(21.4)$ & $18(14.9)$ & $3(4.4)$ & & & \\
\hline Curvilinear & $40(71.4)$ & $103(85.1)$ & $64(94.1)$ & & & \\
\hline
\end{tabular}

Data were tested by Chi-square test or Fisher's exact test when cell counts were $<5 .{ }^{*}$, according to the Bonferroni test, the $\mathrm{P}$ value between UMBO and the other two groups was $<0.016$, and the $\mathrm{P}$ value between COPD and normal group was 0.021 . UMBO, unilateral main bronchus obstruction; COPD, chronic obstructive pulmonary disease.

With the increasing severity of flow limitation in COPD, the percentage of biphasic pattern in expiration increased from $6.7 \%$ to $87.2 \%$ (Table 7). Among the 56 patients in COPD with a biphasic expiratory patten, $78.6 \%(44 / 56)$ of them had various extent of emphysema on chest CT. Meanwhile, the sharp inflections appeared in over $50 \%$ of patients in GOLD 2 and GOLD 3, and reached $91.2 \%$ of GOLD $4(n=31)$.

\section{Differentiation between $\mathrm{UMBO}$ and COPD}

PSM were used to adjust age and gender in these two groups when expiratory F-V curve patterns were both biphasic, and eventually, there were 24 patients respectively in UMBO and COPD group. Binary logistic regression was used to explore the related factors of identifying UMBO from COPD which turned out with good fit. The 
Table 5 Cross tabulation of breakpoints between UMBO and COPD groups

\begin{tabular}{|c|c|c|c|c|c|}
\hline Parameters & UMBO $(n=32)$ & $\operatorname{COPD}(n=56)$ & $\chi^{2}$ & $P$ & Cramer's V \\
\hline \multicolumn{6}{|c|}{ Location of breakpoints, \% } \\
\hline$>\mathrm{MEF}_{75}$ & $9(28.1)$ & $54(96.4)$ & 47.42 & $<0.001$ & 0.73 \\
\hline $\mathrm{MEF}_{75}-\mathrm{MEF}_{50}$ & $16(50.0)$ & $2(3.6)$ & & & \\
\hline$<\mathrm{MEF}_{50}$ & $7(21.9)$ & $0(0)$ & & & \\
\hline \multicolumn{6}{|c|}{ Angle of breakpoints, \% } \\
\hline Sharp & $1(3.1)$ & $46(82.1)$ & 51.10 & $<0.001$ & 0.76 \\
\hline Blunt & $31(96.9)$ & $10(17.9)$ & & & \\
\hline
\end{tabular}

Data were tested by Chi-square test or Fisher's exact test when cell counts were $<5$. UMBO, unilateral main bronchus obstruction; COPD, chronic obstructive pulmonary disease; $\mathrm{MEF}_{50}$, maximal expiratory flow with $50 \%$ of $\mathrm{FVC}$ expired; $\mathrm{MEF}_{75}$, maximal expiratory flow with $25 \%$ of FVC expired, peak expiratory flow.

logistic model (bivariable model 1) was able to correctly classify $87.7 \%$ of the research subjects. The sensitivity of the model was $95.0 \%$, the specificity was $76.0 \%$. The angle and the location of breakpoint were shown to be the optimum factors along with higher accuracy. The location of breakpoints between $\mathrm{MEF}_{75}$ and $\mathrm{MEF}_{50}(\mathrm{OR}=8.00$, $\mathrm{P}=0.031)$ and blunt angle $(\mathrm{OR}=16.63, \mathrm{P}=0.004)$ were more likely to be UMBO, compared with those breakpoints between $\mathrm{MEF}_{75}$ and $\mathrm{MEF}_{50}$ with sharp angle (Table 8).

\section{Discussion}

$\mathrm{UMBO}$ is attracting more attention because confirmation by CT scan is readily available and more therapeutic modalities are offered by interventional bronchoscopy. Gascoigne et al. (3) first reported a biphasic expiratory flow pattern with an end inspiratory "tail" in patients with UMBO, and when bronchial stenosis was relieved by insertion of a stent, the F-V curve returned to normal contours. Then the biphasic pattern in expiration or inspiration was considered to be the possible sign of UMBO $(5,8)$. Additionally, the biphasic expiratory pattern was confirmed and further analyzed in diseases with airflow limitation $(9,10)$. The two-compartment lung model could possibly explain the physiological mechanism of a biphasic F-V curve presented in UMBO (11-14), that is, units from the partially obstructed bronchus will likely empty more slowly than those peripheral to the patent bronchus, resulting in the early phase with the lung away from the unobstructed and the late phase from the abnormal bronchus. Moreover, biphasic expiratory F-V curve was also reported in patients with severe obstructive pulmonary diseases $(15,16)$, such as COPD, because of small airway narrowing and airway collapse, resulting in air trapping. As expected, compared to cases with COPD and normal controls, there is a significantly high probability of biphasic pattern in expiration in the UMBO group. The shape of the $\mathrm{F}-\mathrm{V}$ curve tended to be monophasic or curvilinear in normal subjects, none presented with biphasic pattern. Therefore, we confirmed that the expiratory biphasic pattern might be crucial in the identification of UMBO.

The sensitivity and specificity of biphasic inspiratory F-V curve was controversial. Some studies $(2,3)$ supported that the biphasic F-V curve of inspiration was seemingly more specific than that of expiration for recognizing UMBO because the tail at the end of inspiratory F-V curve was not a feature of airway obstruction in general. However, biphasic inspiratory curve was not prevalent $(7.1 \%)$ in our patients consistent with other studies $(4,5,11)$, which might be explained by positive transmural pressure upon inspiration as occurred in intrathoracic stenosis of the trachea $(4,17)$. But when present, it deserved close attention to exclude UMBO.

In essence, the characteristics of breakpoint, the location and angle, was equally important in the differentiation of UMBO with COPD. We speculated that an earlier breakpoint appeared in COPD might be due to a combination of an increase in peripheral airway resistance and a decrease in lung elastic recoil during forced expiration (18), while a later breakpoint observed in UMBO might be explained by the two-compartment lung model in UMBO. It is likely that airway collapsed suddenly during exhalation in COPD, namely downstream compression, resulting in a sharper breakpoint. Stenotic bronchus with relative intact small airways might be one of the reasons of 


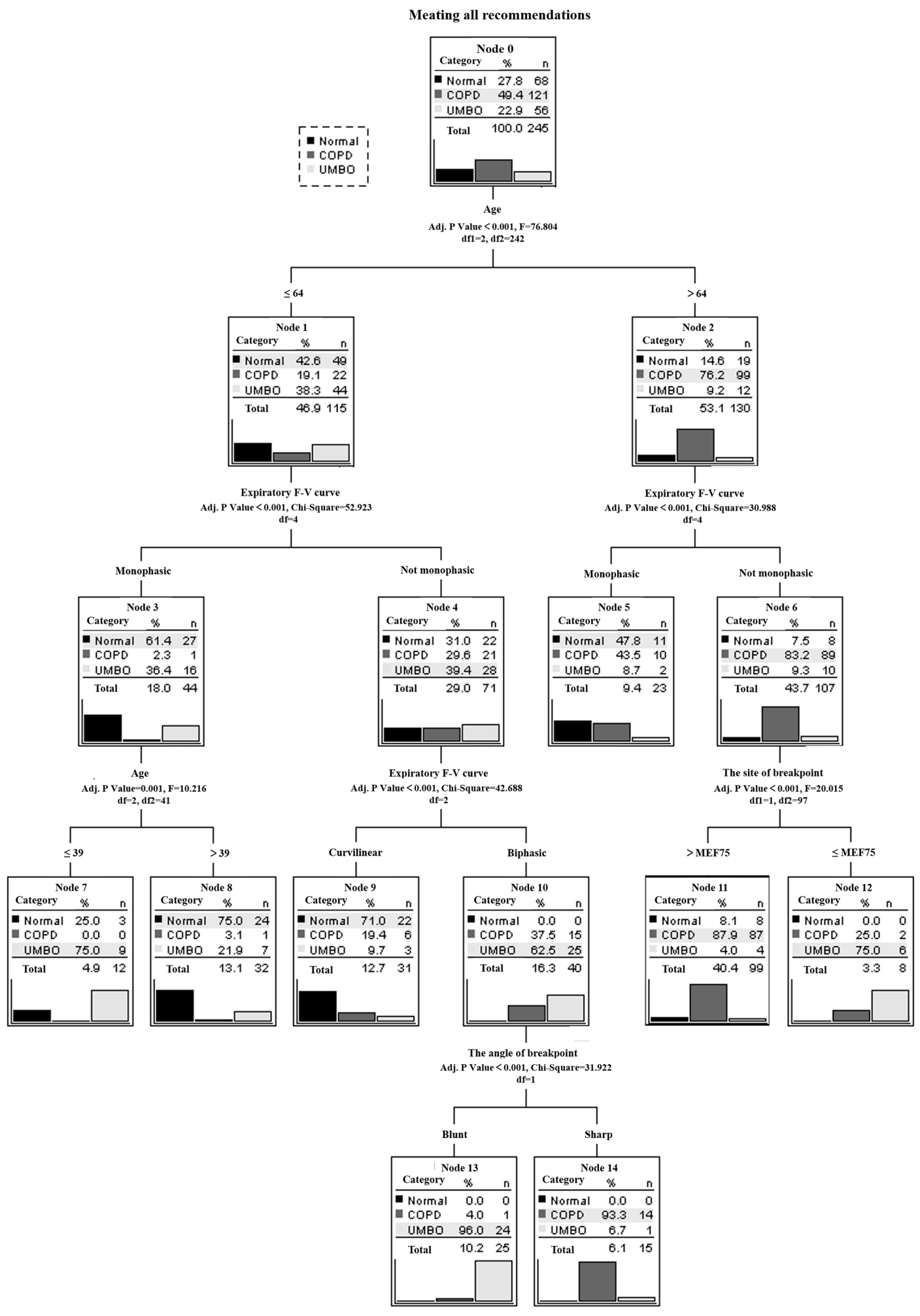

Figure 4 The decision tree of approach to assessing statistically significant variates (year, the pattern of F-V curve, the site and angle of breakpoint; $\mathrm{P}<0.001)$ in normal, COPD, and UMBO groups using the Quick Unbiased Efficient Statistical Tree (QUEST) method. COPD, chronic obstructive pulmonary disease; F-V curve, Flow-volume curve; $\mathrm{MEF}_{75}$, maximal expiratory flow with $25 \%$ of $\mathrm{FVC}$ expired; UMBO, unilateral main bronchus obstruction. 
Table 6 Comparison of expiratory F-V curve pattern and location of breakpoints and degree of stenosis

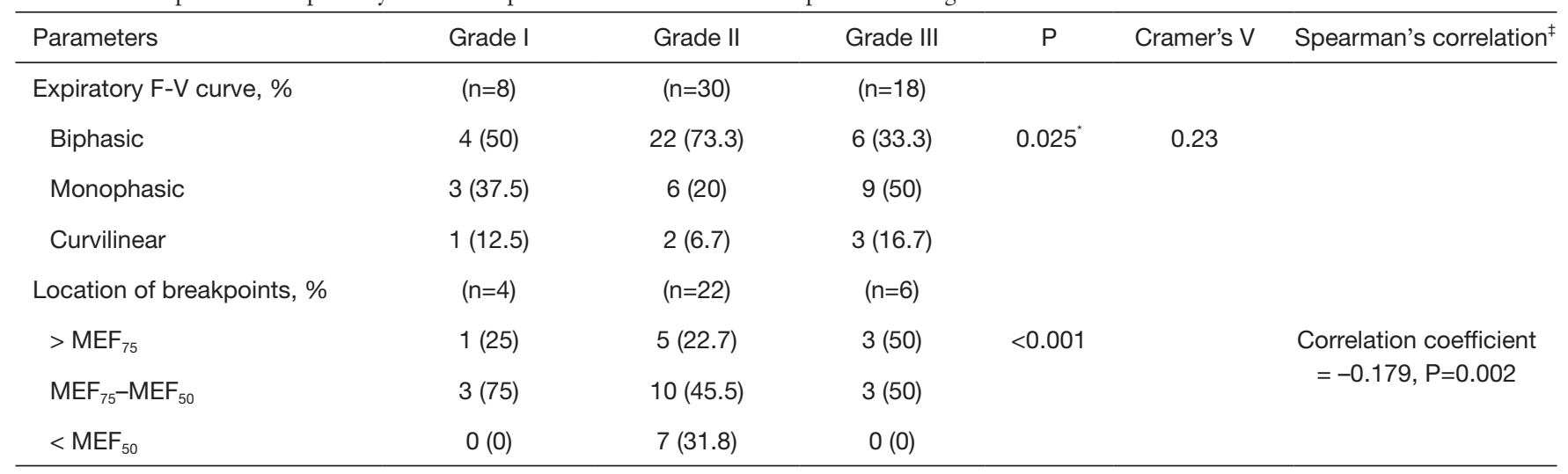

The percentage in each group was tested by Spearman's correlation and Chi-square test or Fisher's exact test when cell counts were less than 5. *, according to the Bonferroni test, the $\mathrm{P}$ value between grade $\mathrm{I}$ and the other two grade groups was $>0.05$, and the $\mathrm{P}$ value between grade II and grade III was 0.021 ; ${ }^{\ddagger}$, the correlation coefficient between grade I and grade II was $0.257(\mathrm{P}<0.001)$, while between grade II and grade III was $-0.406(\mathrm{P}<0.001)$. $\mathrm{MEF}_{50}$, maximal expiratory flow with $50 \%$ of $\mathrm{FVC}$ expired; $\mathrm{MEF}_{75}$, maximal expiratory flow with $25 \%$ of FVC expired, peak expiratory flow.

Table 7 Comparison of expiratory F-V curve pattern and breakpoint angle in different GOLD classification

\begin{tabular}{|c|c|c|c|c|c|c|c|}
\hline Parameters & GOLD 1 & GOLD 2 & GOLD 3 & GOLD 4 & $\chi^{2}$ & $P^{*}$ & Cramer's V \\
\hline Biphasic & $1(6.7)$ & 8 (19.5) & $13(50)$ & 34 (87.2) & 53.27 & $<0.001$ & 0.46 \\
\hline Monophasic & $1(6.7)$ & $5(12.2)$ & $4(15.4)$ & $1(2.5)$ & & & \\
\hline Curvilinear & $13(86.6)$ & 28 (68.3) & 9 (34.6) & 4 (10.3) & & & \\
\hline Sharp & $0(0)$ & $6(75)$ & $9(69.2)$ & $31(91.2)$ & 200.57 & $<0.001$ & 0.71 \\
\hline Blunt & $1(100)$ & $2(25)$ & $4(30.8)$ & $3(8.8)$ & & & \\
\hline
\end{tabular}

The percentage in each group was tested by Chi-square test or Fisher's exact test when cell counts were less than $5 .{ }^{*}$, according to the Bonferroni test, the $P$ value between GOLD 4 and GOLD 1 was <0.001, between GOLD 3 and GOLD 1 was 0.012 , as well as between GOLD 4 and GOLD 2 was $<0.001$, but the $P$ values of other comparisons were $>0.05$; ${ }^{\ddagger}$, according to the Bonferroni test, the $P$ value between GOLD 1 and the other GOLD classification was $<0.001$, but the $\mathrm{P}$ values of other comparison were $>0.01$.

a blunter breakpoint in patients with UMBO. Additionally, this study revealed that the biphasic F-V curve of expiration with abrupt breakpoint is more likely to be in severe COPD. Rather, it did not happen in COPD with mild airway limitation. Theoretically, as COPD progressed, the degree of loss of lung recoil aggravated with the extent of emphysema, accompanied with the increase of peripheral airways resistance, which was reflected in a biphasic contour of F-V curve with a definite inflection point (18).

In matching case of expiratory biphasic F-V curve, it is more likely to be $\mathrm{UMBO}$ for a patient with a blunt breakpoint located between $\mathrm{MEF}_{75}$ and $\mathrm{MEF}_{50}$. On the other hand, it is more probable to be COPD for those with sharp breakpoint located ahead of $\mathrm{MEF}_{75}$.

Besides, it has been reported that the degree of tracheal stenosis was associated with a characteristic change in the F-V curve (19). In this study we found that a monophasic F-V curve mostly appeared with either mild ( $\leq 50 \%$, grade I) or most severe ( $>90 \%$, grade III) bronchial stenosis. It was demonstrated that a monophasic F-V curve appeared with near-normal ventilation or near-complete obstruction, resulting in only one phase without slope alteration (4). Previous study suggested breakpoints move in the direction of high volume and low flow with advancing degree of UMBO (4). In terms of this study, an earlier breakpoint, almost sited ahead of $\mathrm{MEF}_{50}$ or even $\mathrm{MEF}_{75}$, although just 
Table 8 Logistic regression analyses for differentiation between UMBO and COPD

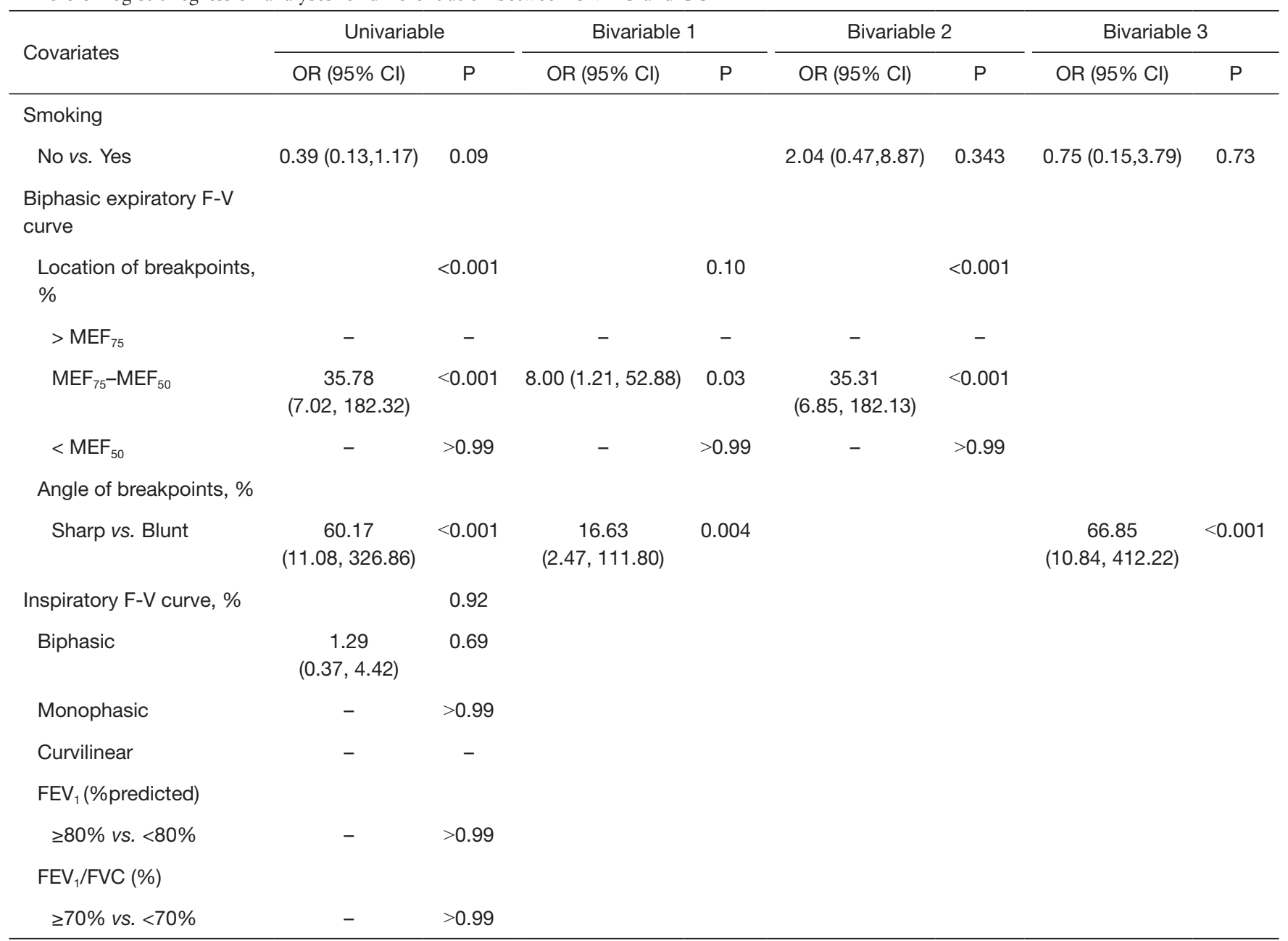

Data were $\mathrm{n}(\%)$ or median (IQR). $\mathrm{Cl}$, confidence interval; $\mathrm{FEV}_{1}$, forced expiratory volume in one second; $\mathrm{FEV}_{1} / \mathrm{FVC}$, the ratio of forced expiratory volume in one second and forced vital capacity; $\mathrm{MEF}_{50}$, maximal expiratory flow with $50 \%$ of $\mathrm{FVC}_{\mathrm{V}}$ expired; $\mathrm{MEF}_{75}$, maximal expiratory flow with $25 \%$ of FVC expired; OR, odds ratio.

a minority, was usually depicted in grade I or grade III. However, it was inconsistent with the previous study, and the reason was unknown and remained to be answered.

There are several limitations in this study. Firstly, it was a retrospective study with small sample size, in which data was not Gaussian distributed. In multivariate analysis, the number of variables for analysis were limited with wide $95 \%$ confidence intervals. Nevertheless, significant differences of $\mathrm{F}-\mathrm{V}$ patterns, especially in biphasic F-V curve, still existed. Secondly, lacking of comparison with other airway diseases, or different obstructive types and degrees of obstruction probably increase the risk of bias. On top of those, as clinicians, we are aware that typical patterns of maximum inspiratory and expiratory $\mathrm{F}-\mathrm{V}$ curves are just hint to the possibility of UMBO, direct observation either by bronchoscope or radiological techniques are a must to confirm its presence and severity. Thus, further study is needed for validation of present findings.

In summary, we found that biphasic expiratory F-V loop was prevalent in $\mathrm{UMBO}$, and the location of breakpoints between $\mathrm{MEF}_{75}$ and $\mathrm{MEF}_{50}$ with blunt angle was more likely to be seen in UMBO, compared with earlier and sharper breakpoints in COPD. In our study, biphasic F-V curve usually appeared in grade II (51-90\%) bronchial stenosis. More validations are needed in clinical practice and more specific features of F-V curve in $\mathrm{UMBO}$ warranted further investigation. 


\section{Acknowledgments}

We would like to express our gratitude to all the mentors for their teaching, their continuous encouragement and guidance, to all the colleagues at the department of pulmonary and critical care medicine, for their helpful discussion and advice, and finally to technicians in bronchoscopy suite and lung function lab for their assistance in data retrieval.

Funding: None.

\section{Footnote}

Reporting Checklist: The authors have completed the STROBE reporting checklist. Available at http://dx.doi. org/10.21037/jtd-20-2649

Data Sharing Statement: Available at http://dx.doi. org/10.21037/jtd-20-2649

Peer Review File: Available at http://dx.doi.org/10.21037/jtd20-2649

Conflicts of Interest: All authors have completed the ICMJE uniform disclosure form (available at http://dx.doi. org/10.21037/jtd-20-2649). All authors have no conflicts of interest to declare.

Ethical Statement: The authors are accountable for all aspects of the work in ensuring that questions related to the accuracy or integrity of any part of the work are appropriately investigated and resolved. The study was conducted in accordance with the Declaration of Helsinki (as revised in 2013). The study was approved by the Research Ethics Committee of the Faculty of Biomedicine, Peking University First Hospital [Institutional Review Board (IRB), approval number: 2020-123] with a waiver of informed consent.

Open Access Statement: This is an Open Access article distributed in accordance with the Creative Commons Attribution-NonCommercial-NoDerivs 4.0 International License (CC BY-NC-ND 4.0), which permits the noncommercial replication and distribution of the article with the strict proviso that no changes or edits are made and the original work is properly cited (including links to both the formal publication through the relevant DOI and the license). See: https://creativecommons.org/licenses/by-nc-nd/4.0/.

\section{References}

1. Modrykamien AM, Gudavalli R, McCarthy K, et al. Detection of upper airway obstruction with spirometry results and the flow-volume loop: a comparison of quantitative and visual inspection criteria. Respir Care 2009;54:474-9.

2. Anzueto A, Levine SM, Tillis WP, et al. Use of the flowvolume loop in the diagnosis of bronchial stenosis after single lung transplantation. Chest 1994;105:934-6.

3. Gascoigne AD, Corris PA, Dark JH, et al. The biphasic spirogram: a clue to unilateral narrowing of a mainstem bronchus. Thorax 1990;45:637-8.

4. Ko Y, Yoo JG, Yi CA, et al. Changes in the flow-volume curve according to the degree of stenosis in patients with unilateral main bronchial stenosis. Clin Exp Otorhinolaryngol 2015;8:161-6.

5. Mazzei JA, Barro A, Mazzei ME, et al. Biphasic flow volume curve due to obstruction of main bronchus by bronchogenic cyst. Respir Med CME 2011;4:116-8.

6. Freitag L, Ernst A, Unger M, et al. A proposed classification system of central airway stenosis. Eur Respir J 2007;30:7-12.

7. Empey DW. Assessment of upper airways obstruction. $\mathrm{Br}$ Med J 1972;3:503-5.

8. Choi SJ, Jo MS, Lee HP, et al. A case of biphasic flowvolume loop in left mainstem bronchial stenosis. Tuberc Respir Dis 1998;45:416-20.

9. Neagos GR, Martinez FJ, Deeb GM, et al. Diagnosis of unilateral mainstem bronchial obstruction following single lung transplantation with routine spirometry. Chest 1993;103:1255-8.

10. Villaran Y, Sekela ME, Burki NK. Maximal expiratory flow patterns after single-lung transplantation in patients with and without chronic airways obstruction. Chest 2001;119:163-8.

11. Gelb AF, Tashkin DP, Epstein JD, et al. Physiologic characteristics of malignant unilateral main-stem bronchial obstruction: diagnosis and Nd-YAG laser treatment. Am Rev Respir Dis 1988;138:1382-5.

12. Revelly JP, Feihl F, Liebling T, et al. Time constant histograms from the forced expired volume signal: a clinical evaluation. Eur Respir J 1989;2:536-42.

13. Roos CM, Braat MC. End-inspiratory flow reduction in the forced flow-volume curve as a sign of unilateral bronchial disease. Neth J Med 1985;28:378-82.

14. Breen PH, Serina ER, Barker SJ. Exhaled flow monitoring 
can detect bronchial flap-valve obstruction in a mechanical lung model. Anesth Analg 1995;81:292-6.

15. Pellegrino R, Viegi G, Brusasco V, et al. Interpretative strategies for lung function tests. Eur Respir J 2005;26:948-68.

16. Husain A, Habib SS. Pattern identification of obstructive and restrictive ventilatory impairment through flow volume curves. Pak J Physiol 2008;4:30-4.

17. Murray JF, Mason RJ. Murray and Nadel's textbook of

Cite this article as: Sun W, Wang GF, Zhang W, Zhang H, Liu Y, Que CL. Characteristics of unilateral main bronchus obstruction and differentiation from chronic obstructive pulmonary disease by spirometry. J Thorac Dis 2021;13(4):22642275. doi: $10.21037 /$ jtd-20-2649 respiratory medicine. 5 th ed, Philadelphia: Saunders Elsevier, 2010.

18. Jayamanne DS, Epstein H, Goldring RM. Flow-volume curve contour in COPD: correlation with pulmonary mechanics. Chest 1980;77:749-57.

19. Miller RD, Hyatt RE. Obstructing lesions of the larynx and trachea: clinical and physiologic characteristics. Mayo Clin Proc 1969;44:145-61. 